Atmosphere", by H. H. Hess ; "The Origins of Life", by George Wald. The second section comprises the chapters on: "Symmetry and Conservation Laws", by Eugene P. Wigner; "Elementary Particles", by Geoffrey F. Chew; "The Structure of Nuclei", by Victor F. Weisskopf; "The Architecture of Molecules", by Linus Pauling; "The Organization of Living Matter", by George E. Palade. The third section deals with "The Determinants and Evolution of Life", which was introduced by Theodosius Dobzhansky and contains the lectures on "Genetic Determinants", by E. L. Tatum; "The Differentiation of Cells", by T. M. Sonneborn; "The Influence of the Environment", by G. Evelyn Hutchinson; "The Evolution of Living Systems", by Ernst Mayr; "The Physiological and Cultural Determinants of Behaviour", by Neal E. Miller. The fourth section was devoted to "The Scientific Endeavour" and consisted of lectures in "Communication and the Comprehension of Scientific Knowledge", by Robert Opponheimer; "The Role of Science in Universities, Government and Industry: Science and Public Policy", by Jerome B. Wiesner; "Synthesis and Applications of Scientific Knowledge for Human Use", by J. B. Fisk; and "Science in the Satisfaction of Human Aspiration", by I. I. Rabi. The final section was devoted to a lecture by President John F. Kennedy on "A Century of Scientific Conquest". The book concludes with a bibliography of references for each of the lectures.

The eminence of each of the scientists who contributed to the occasion would indicate that each of the chapters is masterly both as an essay in science and in exposition. The whole book is a remarkable achievement, and the amount of consistently connected and developed information which it contains, particularly at so low a price, is remarkable. It should find many readers: the undergraduate, the graduate and the specialist in science. It should prove a means of obtaining a scholarly introduction to broad fields in the sciences.

W. L. SUmner

\section{PLANT PHENOLICS}

\section{Methods in Polyphenol Chemistry}

Proceedings of the Plant Phenolics Group Symposium, Oxford, April 1963. Edited by J. B. Pridham. Pp. ix + 146. (Oxford, London and New York: Pergamon Pross, 1964.) 50s.

$\mathrm{A}^{\mathrm{P}}$

PART from their intrinsic interest, deriving from the existence of a multitude of variations based on a relatively simple structure and their aesthetic interest as the source of a large proportion of the pigments which provide colour in plants, the plant phenolics have great importance, as a group, as an aid to plant classification by chemo-taxonomic techniques. Yet until quite recently the difficulties involved in their adequate separation and characterization were so great, and the methods so tedious, as to render their employment almost entirely impracticable.

Thus although among the most easily extractable and most visually characteristic of all plant compounds, it was only with the development of paper chromatography over the past fifteen or twenty years that their potential became exploitable. Particular interest therefore attaches to the symposium of the Plant Phenolics Group in April 1963, which is now published under the title Methods in Polyphenol Chemistry, and which was particularly concerned with the methods and techniques of analysis and characterization which has made this development possible.

Separation largely depends on chromatography, and as would be expected, a large part of the symposium was devoted to descriptions of the various techniques which have been found useful. These include contributions on paper chromatography by Bate-Smith, which contains a most necessary plea for standardization wherever possible of solvents; on the use of thin-layer chromatography by Thaller; a particularly encouraging discussion of the use of the new polyamides by Horhammer; and a description of the application of gas-liquid chromatography by Norman and his colleagues. In addition there are two papers on the closely related subject of electrophoresis by Weigel and by Pridham, although it is pointed out that owing to its greater complexity this technique does not provide a substitute for chromatography, but may be a useful complementary tool for particular applications.

Just as chromatography has transformed the problem of separation, so spectroscopic methods have greatly simplified quantitative measurement and identification, and contributions at the symposium included papers by Harborne on the use of ultra-violet spectroscopy, with special attention to the relationship between structure and spectra and the use of the technique in the identification of new compounds; infra-red spectroscopy of flavonoids by Wagner; a description of preliminary attempts to make use of the sensitivity characteristic of spectrofluorimetry by Bridges; and a brief discussion on the basic principles of nuclear magnetic resonance spectroscopy by Abraham, with examples of its application to the determination of molecular structure in phenolics.

The final paper by Swain and Goldstein is concerned with the quantitative analysis of phenolic compounds, and is particularly notable for its cautionary approach, pointing out in respect to a number of possible techniques that while there is comparatively little difficulty in obtaining values of a sort, great care is needed to ensure that these are comparable and therefore meaningful, and the paper makes clear that a considerable amount of effort has been wasted as a result of failure to take this precaution.

Collectively the papers provide an excellent introduction to the range of techniques available for separation and analysis of phenolic compounds, though as a rule the scope of the particular techniques described is less well defined, and their limitations tend to be omitted. Individually the papers are well presented and highly readable, providing a high quota of information without being exhaustive or exhausting, and the volume can be recommended confidently to anyone interested in the subject. The book lacks an index, and even though the need for this is to some extent obviated by its shortness and division into clearly defined papers, this omission makes it unnecessarily difficult to look for information about particular compounds. This is unfortunate when one considers the very considerable amount of physical data relating to individual phenols which is contained in the various tables and figures.

P. A. Thompson

\section{OCEANOGRAPHY FOR ENGINEERS}

\section{Oceanographical Engineering}

By Prof. Robert L. Wiegel. (Prentice-Hall International Series in Theoretical and Applied Mechanics. Fluid Mechanics Series.) Pp. xi+532. (Englewood Cliffs, N.J., and London: Prentice-Hall, Ine., 1964.) 108s.

T is realistic and progressive to maintain that hydraulic engineering should reach down river estuaries as far as low-water mark, and that oceanographic engineering should extend up the rivers as far as high-water mark. Prof. Wiegel, who holds the chair of civil engineering in the University of California at Berkeley, has such wide experience, and his new and detailed book Oceanographical Engineering can be recommended as a comprehensive guide especially to engineers engaged in coastal and harbour engineering. It gives much information that is essential to structural design but is more particularly outstanding in its description and appreciation of the factors that are likely to influence functional design and 